\title{
Postoperative urinary infections caused by Escherichia coli
}

\author{
K. A. BETTELHEIM, ${ }^{1}$ C. DULAKE, ${ }^{2}$ AND JOAN TAYLOR \\ From the Salmonella Reference Laboratory, Colindale, and King's College Hospital, London
}

SYNOPSIS Serological and biochemical classification of Esch. coli from the rectum and vagina of patients who developed a urinary infection after operation and the insertion of a self-retaining catheter showed that 13/20 urinary infections were caused by a type which had been present before operation in the rectum, vagina, or both.

In a study of the effects of the indwelling urinary catheter after gynaecological operations, Chamberlain, Dulake, and Kidd (1968) showed that $39 \%$ of patients who had previously been free of infection developed infections of the urinary tract within 12 days of operation. The three groups of organisms most commonly implicated were Escherichia coli, Proteus spp, and enterococci. The origin of these infections is a matter of some interest and with this end in view we studied in detail 20 strains of Esch. coli derived from the urine of patients who had had indwelling catheters and compared them with the strains which had been present in the rectum and vagina before operation.

\section{Methods and Materials}

The operations were performed at King's College Hospital, London (Chamberlain et al, 1968). The organisms present before operation were isolated from rectal and high vaginal swabs and the postoperative ones from the urine. When a short set of routine tests had confirmed that the organisms belonged to the Esch. coli group they were cultured and stored on nutrient agar slopes. Most of them were examined by us within four weeks of isolation.

The strains were examined by biochemical and serological methods which have been described (Bettelheim and Taylor, 1969). We recorded their ability to metabolize the following 16 substrates: lactose, sucrose, salicin, dulcitol, inositol, adonitol, raffinose, sorbitol, arabinose, rhamnose, xylose, trehalose, glycerol, cellobiose, maltose, and sorbose.

Present addresses:

${ }^{1}$ Department of Biochemistry, Imperial College, London.

'Public Health Laboratory, St Luke's Hospital, Guildford.

Received for publication 30 September 1970.
The results were observed up to seven days. The somatic 0 , surface $\mathrm{K}$, and flagellar $\mathrm{H}$ antigens were identified using $147 \mathrm{OK}$ and $49 \mathrm{H}$ antisera which are in constant use. Most strains could be identified in

\begin{tabular}{|c|c|c|c|}
\hline Serotype & Rectum & Vagina & Urine \\
\hline 01K ?H7 & 1 & & \\
\hline 01K ?H34 & & & 1 \\
\hline $\begin{array}{l}01 \mathrm{~K} \text { ?H- } \\
02 \mathrm{~K} ? \mathrm{H} 1\end{array}$ & 1 & & 1 \\
\hline $\begin{array}{l}\text { 02K ?H1 } \\
\text { 02K?H4 }\end{array}$ & 3 & & \\
\hline 02K?H- & 1 & & 1 \\
\hline 04K3H5 & & & 1 \\
\hline 05K ?H4 & 1 & & \\
\hline 06K13H1 & & 1 & 2 \\
\hline 06K?H1 & & 1 & 1 \\
\hline 07K ?H- & 1 & & \\
\hline $011 \mathrm{~K}$ ?H- & 1 & & \\
\hline $017 \mathrm{~K} 16 \mathrm{H} 18$ & 1 & & \\
\hline 018ac.K ?H12 & 1 & & \\
\hline 023K ?H15 & 1 & & \\
\hline 029K ?H- & 1 & & \\
\hline $031 \mathrm{~K}$ ?H4 & 1 & & 1 \\
\hline 031K ?H7 & & & 1 \\
\hline 036K ?H5 & 1 & & \\
\hline 075K ?H5 & 1 & 3 & 3 \\
\hline 076K ?H17 & & 1 & \\
\hline 083K ?H4 & & & 1 \\
\hline 036K ?H5 & 1 & & \\
\hline $\begin{array}{l}\text { 075K ?H5 } \\
\text { 076K ?H17 }\end{array}$ & 1 & $\begin{array}{l}3 \\
1\end{array}$ & 3 \\
\hline 083K ?H4 & & & 1 \\
\hline 0100K ?H- & 1 & 1 & 1 \\
\hline 0103K ?H19 & 1 & 1 & 1 \\
\hline $0125 \mathrm{~K} 70 \mathrm{H} 30$ & 1 & & \\
\hline OK ?H-1 $^{-1}$ & & 1 & \\
\hline 0141K85H32 & & 1 & 1 \\
\hline 0?K ?H4 & & & 1 \\
\hline 0 ?K ?H10 & & $\begin{array}{l}1 \\
1\end{array}$ & 2 \\
\hline 0 rough $\mathrm{H}$ - & & 1 & 1 \\
\hline Totals & 19 & 12 & 20 \\
\hline
\end{tabular}

Table I Number of serotypes of Esch. coli isolated from rectum and vagina preoperatively and from urine postoperatively in 20 patients

${ }^{1} \mathrm{O}$ antigen related to 0129 
accordance with the international scheme proposed by Kauffmann (1944 and 1966).

\section{Results}

Twenty patients suffered from postoperative urinary infection due to $E$. coli. Table I lists the numbers of each serotype which were isolated from pre- and postoperative specimens.

Three patients yielded the same serotype from all three sites (Table II). In one other the same serotype $031 \mathrm{~K}$ ?H4 was found in the rectal swab and the urine but not in the vagina. In two further patients the strains isolated from the urine and the rectum in each case gave the same biochemical reactions and had the same 0 and $\mathrm{K}$ structures; the $\mathrm{H}$ antigens were different (Table III).

\begin{tabular}{ll}
\hline Patient & Rectum, Vagina, Urine \\
\hline A & $0100 \mathrm{~K}$ ?H- \\
B & $0103 \mathrm{~K} ? \mathrm{H} 19$ \\
C & $075 \mathrm{~K}$ ? 5 \\
\hline
\end{tabular}

Table II Isolation of same serotype of Esch. coli from vagina and rectum preoperatively and urine postoperatively in three patients

\begin{tabular}{llll}
\hline Patient & Rectum & Vagina & Urine \\
\hline D & 02K ?H4 & -1 & $02 \mathrm{~K}$ ?H1 \\
E & 02K ?H4 & - & 02K ?H-
\end{tabular}

Table III Isolations of E. coli giving identical biochemical reactions and closely related serological reactions from preoperative rectal swabs and urine

1 - = No E. coli isolated

We have already met this kind of antigenic variation (Bettelheim and Taylor, 1969).

The seven patients in Table IV yielded identical types in the vagina and urine but a different one in

\begin{tabular}{llll}
\hline Patient & Rectum & Vagina & Urine \\
\hline F & -1 & 0?K ?H10 & 0?K ?H10 \\
G & - & 0 rough H- & 0 rough H- \\
H & $017 \mathrm{~K} 16 \mathrm{H} 18$ & $0141 \mathrm{~K} 85 \mathrm{H} 32$ & 0141 K85H32 \\
J & $023 \mathrm{~K}$ ?H15 & $075 \mathrm{~K}$ ?H5 & 075K ?H5 \\
K & - & $075 \mathrm{~K}$ ?H5 & 075K ?H5 \\
L & 07K ?H- & 06K ?H1 & 06K ?H1 \\
M & 01K ?H- & 06K13H1 & 06K13H1 \\
\hline
\end{tabular}

Table IV Isolations of same serotype of Esch. coli from vagina preoperatively and from urine postoperatively

$1-=$ specimen not taken the rectum. In the remainder the types isolated from the three sites were apparently distinct (Table V).

The results are summarized in Table VI.

\begin{tabular}{llll}
\hline Patient & Rectum & Vagina & Urine \\
\hline $\mathrm{N}$ & $018 \mathrm{acK}$ ?H12 & $-{ }^{1}$ & $083 \mathrm{~K}$ ?H4 \\
$\mathrm{P}$ & $\{02 \mathrm{~K}$ ?H- & - & $06 \mathrm{~K} 13 \mathrm{H} 1$ \\
& $0125 \mathrm{~K} 70 \mathrm{H} 30$ & & \\
$\mathbf{Q}$ & $05 \mathrm{~K}$ ?H4 & - & $01 \mathrm{~K}$ ?H34 \\
$\mathbf{R}$ & $02 \mathrm{~K}$ ?H4 & $076 \mathrm{~K}$ ?H17 & $0 ? \mathrm{~K}$ ?H10 \\
& $036 \mathrm{~K}$ ?H5 & - & \\
$\mathbf{T}$ & $01 \mathrm{~K}$ ?H7 & - & $04 \mathrm{~K} 3 \mathrm{H} 5$ \\
$\mathrm{U}$ & $029 \mathrm{~K}$ ?H- & - & $0 ? \mathrm{~K}$ ?H4 \\
& $011 \mathrm{~K}$ ?H- & - & $031 \mathrm{~K}$ ?H7 \\
\hline
\end{tabular}

Table V Isolations of different strains of Esch. coli from vagina and rectum preoperatively and from urine postoperatively

1

No. of Patients

The same serotype in the urine and in both rectum

$\begin{array}{lllllll}\text { and vagina } & \ldots & \ldots & \ldots & \ldots & \ldots & 3\end{array}$

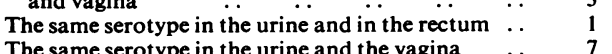

The same serotype in the urine and the vagina ..

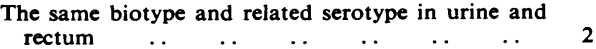

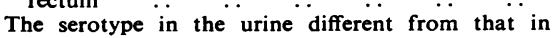

$\begin{array}{lllllll}\text { rectum or vagina } & \ldots & \ldots & \ldots & \ldots & \ldots & 7\end{array}$

20

Table VI Association of serotypes causing urinary infection after operation with the presence of the same serotypes in rectum and vagina before operation

\section{Discussion}

While $13 / 20$ patients in this series were shown to harbour the same or similar serotypes of Esch. coli in a site adjoining the urinary tract as that which caused a urinary infection, the mechanism of infection and the route by which it spread is still open to argument.

Testing these strains by biochemical methods added little information which was not provided by the serological classification.

No evidence of cross infection between patients was detected.

We thank Dr Chamberlain for clinical data.

References

Bettelheim, K. A., and Taylor, J. (1969). A study of Escherichia coli isolated from chronic urinary infection. J. med. Microbiol., 2, 225-236.

Chamberlain, G., Dulake, C., and Kidd, E. (1968). Indwelling urinary catheterization. Brit. J. Urol., 40, 315-320.

Kauffmann, F. (1944). Untersuchungen über die Körper-Antigene der Coli-Bakterien. Acta path. microbiol. scand., 21, 46-64.

Kauffmann, F. (1966). The Bacteriology of Enterobacteriaceae. Munksgaard, Copenhagen. 